\title{
Accounting for total work in labour statistics
}

\author{
Andrea Brandolini ${ }^{1} \cdot$ Eliana Viviano $^{1}$
}

Published online: 19 August 2016

(C) The Author(s) 2016. This article is available at SpringerLink with Open Access.

\begin{abstract}
The interest for household production has grown since the release of the new System of National Accounts in 2008. In this paper we analyse how accounting for own-use production may affect labour statistics. Traditional headcount ratios may not be very informative when employment rates consider both home and market production, as most people are engaged in at least one of those activities. Hence, we propose a general class of indices based on the hours spent on each type of work that encompasses headcount indicators as a special case. Our empirical analysis based on time use data for a selected group of countries shows that international rankings are sensitive to the shift from headcounts to hour-weighted indices and that accounting for own-use production changes considerably the picture on the work burden of men and women.
\end{abstract}

Keywords Home production - Work intensity ·

Employment rate

JEL J22 · J21

\section{Der Gesamtbetrag der Arbeit in den Arbeitsmarktstatistiken}

Zusammenfassung Das Interesse an der Haushaltsproduktion ist 2008 nach der Veröffentlichung des neuen Systems der volkswirtschaftlichen Gesamtrechnungen stark gewachsen. In diesem Beitrag analysieren wir, wie die Berücksich-

Eliana Viviano

eliana.viviano@bancaditalia.it

1 Directorate General for Economics, Statistics and Research, Bank of Italy, Rome, Italy tigung der Haushaltsproduktion die Arbeitsmarktstatistiken beinflussen kann. Wenn man erkennt dass die meisten Leute mindestens in einer der beiden Aktivitäten taetig sind und deshalb die Beschäftigungsquoten gleichzeitig Haushaltsund Marktproduktion einbeziehen muessen, sind die üblichen Kopfzahlquoten kaum mehr informativ. Daher unser Vorschlag, eine allgemeine Klasse von auf Arbeitstunden basierten Indikatoren zu erzeugen, die Kopfzahl als Spezialfall einschliessen. Unsere empirische Analyse bezieht sich auf Zeitverwendungsumfragen einer ausgewählten Gruppe von Ländern. Sie zeigt, dass das internationale Ranking vom Umschalten von Kopfzahl- auf Stundengewichteten Indikatoren abhängig ist und dass die Berücksichtigung der Eigengebrauchproduktion die respektiven Arbeitsbelastungen der Frauen und der Männer verändert.

\section{Introduction}

Many activities carried out daily by individuals, such as housekeeping and care for dependent family members, are often defined as home production, as opposed to employment. Whereas employment is aimed at the production of goods and services which are sold in the market, home production is carried out for own consumption. The distinction does not depend on the intrinsic nature of the goods or services produced, but rather on their destination: sale in the market vs. own use by the person, or some other individuals linked to him/her by family ties or friendship. The quantity of labour typically measured by official statistics for a market economy misses the time worked in home production.

The importance of accounting for the aggregate value of home production has been long recognised (e. g. Nordhaus and Tobin 1973; Weinrobe 1974; see also references 
in Chaudeau 1985), whereas the consideration of how total time is allocated among market work, non-market work, and leisure has been central to the modelling of household economic behaviour since the seminal article by Becker (1965). Somewhat less attention has been paid to the implications for the assessment of employment levels and more generally the analysis of labour markets.

The standard definition of the employment rate refers to a social arrangement that values certain activities only if they are carried out in the market, i.e. if they contribute to gross domestic product. Thus, childcare counts for the employment rate when performed by a paid nanny, but not when performed by a grandparent, although the services provided and the effects on child well-being might be similar. In the face of the unanimously recognised value of household work for both output and welfare aggregate estimates, the persistence of such a distinction may reflect the lack of reliable data and the need to use imputation procedures. Substantial improvements on both sides allow us to move forward, but standard labour market statistics need to be reconsidered to account for household work. In particular, headcount ratios may not be very revealing: during the week, an overwhelming majority of people engages in household activities, when broadly defined. Focusing on the "intensity" of this engagement provides a possible solution: what matters is, then, how much time is spent in working at home vis-à-vis the time spent in paid work, on one side, and leisure and remaining activities, on the other.

In this paper, we propose a general framework to account for household work by extending the notion of generalized employment rate discussed by Brandolini and Viviano (2016a, 2016b). Brandolini and Viviano's class of generalised indices embodies a richer characterisation of the employment status, which considers work intensity, as measured by actual hours of work, rather than the simple dichotomous variable employed/non-employed. An aggregation of the employment status based on hours lends itself quite naturally to be developed to accommodate the time spent in non-market activities. As in Brandolini and Viviano (2016a, 2016b), we continue distinguishing headcount from intensity-weighted rates of work participation. Unlike those papers, however, we focus solely on measures of work engagement at the individual level and ignore the implications for household-level measures. This important issue faces significant data limitations and is left for future research.

The paper is organised as follows. First, we discuss the implications of accounting for home production from a labour market perspective. Second, we introduce our measure of total work for individuals. Next, we briefly describe the data. Our empirical analysis uses time use data drawn from the Multinational Time Use Study (MTUS) database for years 1995-2005 (Gershuny and Fisher 2013).
We then study the distribution of employment, household work and total work in a selected group of advanced countries (France, Germany, Italy, the Netherlands, the United Kingdom and the United States). In the final section, we summarize the main conclusions of the paper.

\section{A glimpse at the literature and the main concepts}

There is an extensive literature on the estimation of the aggregate value of home production. For instance, Gronau (1980: 408) measured individual productivities and estimated that the "... the value of home production associated with the work at home of U.S. wives in 1973 exceeded ... $70 \%$ of the family's money income after taxes". Goldschmidt-Clermont (1982) calculated that the aggregate value of housework in industrialised countries could account for as much as 25 to 40 per cent of the measured gross national product. Subsequent economic research has investigated the impact on income inequality (e.g. Jenkins and O'Leary, 1996; Frick, Grabka and Groh-Samberg, 2012). Home production is viewed as an additional resource, which is available for consumption, and should be added to money income. If individuals are assumed to be equally productive in home production and high-wage workers spend less time in home production than low-wage workers do, then income "extended" to include the value of this production tends to be distributed more equally than money income. Macroeconomic models often incorporate household production. ${ }^{1}$ For example, in a standard real business cycle model, Benhabib et al. (1991) and Baxter and Jermann (1999) show that it can help explaining empirical regularities observed in the relationship between household consumption and income (the so-called excess sensitivity puzzle).

This growing attention extends to official statistics. The new System of National Accounts (2008 SNA) singles out household production as the main problem for defining the range of activities to be recorded in the production accounts. It adopts the following definition:

"The SNA ... includes all production of goods for own use within its production boundary, as the decision whether goods are to be sold or retained for own use can be made even after they have been produced, but it excludes all pro-

\footnotetext{
${ }^{1}$ Some authors argue that home production gives individuals extra utility beyond the consumption of the home produced good. This is typically the case of childcare, as the time spent with children may increase parents' utility (e.g. Connelly and Kimmel 2007; Graham and Green 1984). On the other hand, also working in the market can increase utility beyond the wage earned, as it raises self-esteem and social recognition. This further blurs the boundaries between home production and market work.
} 
Fig. 1 Forms of work and the System of National Accounts 2008; Source: ICLS (2013: 3, Diagram 1)

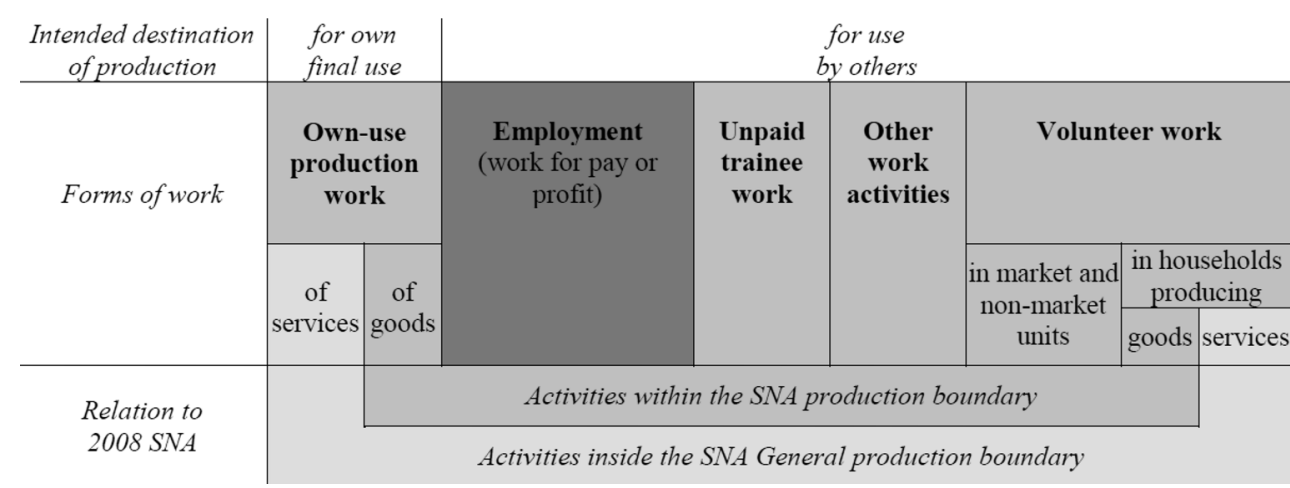

duction of services for own final consumption within households (except for the services produced by employing paid domestic staff and the own-account production of housing services by owner-occupiers). The services are excluded because the decision to consume them within the household is made even before the service is provided" (European Communities et al. 2009: 6-7, par. 1.42).

The 2008 SNA acknowledges that the production of services should be conceptually included within the production boundary, but adopts a compromise solution in order to account for the different uses of the national accounts. In particular, it qualifies the previous choice as follows:

If the production boundary were extended to include the production of personal and domestic services by members of households for their own final consumption, all persons engaged in such activities would become self-employed, making unemployment virtually impossible by definition. This illustrates the need to confine the production boundary in the SNA and other related statistical systems to market activities or fairly close substitutes for market activities (European Communities et al. 2009: 7, par. 1.42). ${ }^{2}$

The principles at the basis of labour statistics have changed accordingly. In the Resolution adopted by the International Conference of Labour Statisticians in 1982, the economically active population comprised all persons engaged in the production of primary products, irrespective of their destination, and of all other goods and services for the market, inclusive of the part allotted by producers to own consumption (see ICLS 1982: par. 5). The Resolution adopted in 2013 takes a far more nuanced view, also in comparison with the 2008 SNA. After calling for a "comprehensive measurement of participation in all forms of work" (ICLS 2013: 2, par. 3), the Resolution excludes activities that do not involve any production, self-care, and all activities that cannot be performed by another person in

2 This concern is somewhat exaggerated, as we could still define as unemployed those who do not have a market job and are looking for it. one's own behalf (ICLS 2013: 2, par. 6). It then identifies five mutually exclusive forms of work (ICLS 2013: 3, par. 7): own-use production work (production of goods and services for own final use); employment work (performed for others in exchange for pay or profit); unpaid trainee work (performed for others without pay to acquire workplace experience or skills); volunteer work (performed for others without pay); and other work activities (e.g. unpaid community service, unpaid work by prisoners). Diagram 1 in the Resolution, reproduced here as Fig. 1, helps understanding the relationship between these forms of work and the 2008 SNA. In particular, it highlights the compromise solution adopted in the 2008 SNA of classifying outside the production boundary the services, but not the goods, produced by someone for own-use or, without any pay, for others.

The framework adopted by the Resolution is consistent with the guidelines issued by a panel study of the $\mathrm{Na}$ tional Research Council (2005), entitled "Beyond the market: Designing nonmarket accounts for the United States" and adopted to construct the satellite accounts for home production in the US (e.g. Landefeld et al. 2009; Bridgman et al., 2012; Suh and Folbre, 2015). In particular, the National Research Council guidelines clearly delimit home production by establishing that it should include only those activities that could be carried out by a third person outside the household, paid at the market wage.

The Resolution provides a detailed characterisation for each of the five forms of work and suggests a set of indicators for monitoring the participation in these activities. In this paper, we focus exclusively on two forms: employment and own-use production work (henceforth, OUP work). Fig. 2 shows the description of the activities comprised in OUP work, for which the Resolution recommends computing headcounts, participation rates and volume measures (ICLS 2013: 15, par. 74). These activities are classified as OUP work regardless of the utility that persons get from them as well as of their perception on whether they are leisure or work. For instance, gardening can be a leisure activity for a person but home production for another one, 
Fig. 2 Definition of persons in own-use production work; Source: ICLS (2013: 5, par. 2)
Persons in own-use production work are defined as all those of working age who, during a short reference period, performed any activity to produce goods or provide services for own final use, where:

(a) "any activity" refers to work performed in the various activities under paragraph 22(b) and (c) for a cumulative total of at least one hour;

(b) production of "goods" (within the 2008 SNA production boundary) covers:

(i) producing and/or processing for storage agricultural, fishing, hunting and gathering products;

(ii) collecting and/or processing for storage mining and forestry products, including firewood and other fuels;

(iii) fetching water from natural and other sources;

(iv) manufacturing household goods (such as furniture, textiles, clothing, footwear, pottery or other durables, including boats and canoes);

(v) building, or effecting major repairs to, one's own dwelling, farm buildings, etc.;

(c) provision of "services" (beyond the 2008 SNA production boundary but inside the General production boundary) covers:

(i) household accounting and management, purchasing and/or transporting goods;

(ii) preparing and/or serving meals, household waste disposal and recycling;

(iii) cleaning, decorating and maintaining one's own dwelling or premises, durables and other goods, and gardening;

(iv) childcare and instruction, transporting and caring for elderly, dependent or other household members and domestic animals or pets, etc.;

(d) "for own final use" is interpreted as production where the intended destination of the output is mainly for final use by the producer in the form of capital formation, or final consumption by household members, or by family members living in other households:

(i) the intended destination of the output is established in reference to the specific goods produced or services provided, as self-declared (i.e. mainly for own final use);

(ii) in the case of agricultural, fishing, hunting or gathering goods intended mainly for own consumption, a part or surplus may nevertheless be sold or bartered. possibly reflecting different social habits or cultural values. However important, these differences do not matter in our paper, as we adopt the SNA framework whereby any activity that can be performed by a third party is classified as OUP work.

\section{Measuring total work}

In Brandolini and Viviano (2016a, 2016b) we argue that the standard headcount employment rate, which takes the ratio of the number of employed persons to the number of persons in the reference population, fails to discriminate among people spending very different time at work. Somebody working one hour in the reference week counts as much as somebody working 40 hours. Hence, we define work intensity as the ratio of the total numbers of hours worked by individual $i$ during a reference period divided by a benchmark. The generalized employment rate index which accounts for work intensity is:
$G E R(\alpha)=\frac{1}{P} \sum_{i=1}^{P} \omega_{i}^{\alpha}, 0 \leq \alpha \leq 1$

where $\omega_{i}$ is the work intensity of individual $i$ and $P$ is the number of people in the reference population (e.g. the working-age population). Work intensity $\omega_{i}$ is not bounded below 1, as some individuals may work more than benchmark hours. Weighting employment according to work intensity is conceptually similar to estimating full-time equivalent (FTE) employment by scaling down part-time employment by a fixed conversion rate (usually, one half). However, measuring work intensity based on the exact amount of hours worked by each individual allows us to take into account the large variety of part time arrangements.

The parameter $\alpha$ governs the "social" evaluation of work participation. The standard headcount employment rate obtains when $\alpha=0 .{ }^{3}$ In this case, the social evaluation assigns a unit value to having a job, regardless of its time arrangements. From this perspective, part-time jobs are equivalent

\footnotetext{
${ }^{3}$ For simplicity's sake, as $\omega_{\mathrm{i}}$ can be equal to 0 , we adopt the convention that 0 to the power of 0 equals 0 .
} 
to full-time jobs. This view can be justified by considering that having a job may be crucial to enhance self-esteem and social integration. At the other extreme, when $\alpha=1$ the index (1) fully takes into account differences in the intensive margin by weighting each individual by the (normalised) time spent at work $\omega_{i}$. The diversity between somebody working one hour in the reference week and somebody not working at all is maximum in the standard employment rate $\operatorname{GER}(0)$, but very small in the intensity-weighted rate $G E R(1)$. An intermediate value of $\alpha$ assigns people working less than the benchmark hoursa weight lower than 1, but by proportionately less than the shortfall in worked hours would imply. Thus, a rather broad range of social concerns can be accounted for by the index (1) by letting $\alpha$ vary between 0 and 1 .

In this paper, we suggest to generalise this framework to account for OUP work in addition to employment. Our aim is to define an index that embodies simple headcount measures as well as an estimate of the total hours spent in both forms of work. Estimates of "total work" defined as the sum of time spent in employment and home production are common in the literature, for instance in the analysis of gender differences in total work supplied by men and women (e.g. Hamermesh 2007; Burda et al. 2013). We define a general class of work participation measures as follows:

$$
\begin{aligned}
& T W R(\alpha, \gamma)= \\
& \left.\frac{1}{P} \sum_{i=1}^{P}\left(\omega_{i}+\gamma v_{i}\right)^{\alpha}, 0 \leq \alpha \leq 1,0 \leq \gamma \leq 1\right) .
\end{aligned}
$$

The variable $v_{i}$ corresponds to $\omega_{i}$ for employment and measuresperson $i$ 's OUP work intensity. As time spent in either type of activities is expressed as a ratio to the total number of hours available in the reference period (e. g. 24 hours if it is a day), it is $0 \leq \omega_{i}+v_{i} \leq 1$; given the time required by self-care, the sum of $\omega_{i}$ and $v_{i}$ actually is below $1 .{ }^{4}$ As before, $\alpha$ determines the social evaluation of time spent working in the market and, when $\gamma>0$, in household production. It varies from valuing participation by itself irrespective of time effort $(\alpha=0)$ to giving it a value proportional to the amount of worked hours $(\alpha=1)$. The second parameter $\gamma$ captures the relative weight of OUP work with respect to employment in the market: setting $\gamma=0$ means that only paid jobs matter for the social evaluation, which is the hypothesis currently underlying the standard employment rate; taking $\gamma=1$ goes in the opposite direction of equating employment and work at home.

\footnotetext{
${ }^{4}$ Whereas in Brandolini and Viviano (2016a, 2016b) we allow for alternative definitions of the benchmark hours, in this paper we take this benchmark to be the total number of hours in the reference period: hence, the intensity indicators cannot exceed 1 .
}

The parameter $\gamma$ determines the degree of substitution of one hour of OUP work for one hour of employment. Choosing a value of $\gamma$ comprised between 0 and 1 means assigning a positive value to hours worked at home, but with a weight lower than those of market work. Using, for instance, lower productivity to justify such an assumption, however plausible it may be, raises the issue of why analogous productivity adjustments are not made for market jobs in different industries or requiring different skills. On the other hand, the method used to evaluate housework could help to pin down the value of $\gamma$ (e.g. GoldschmidtClermont 1982, 1993; Fitzgerald et al. 1996). With an "opportunity cost" valuation, housework must be at least as remunerative as a paid work obtainable in the market. If one hour of paid work is at the margin equivalent to one hour of household work, then it seems natural to set $\gamma$ equal to 1 . However, persons are rarely free to substitute market and non-market activities. The alternative "foregone expenses" valuation focuses on the costs saved by a household by engaging directly in housework. If we compute the cost of replacing the output of the OUP work with goods and services purchased in the market, we can estimate the implicit hourly wage for the OUP work. The ratio of this implicit wage rate to the average wage rate represents the relative price of the OUP work, and it might provide a reference for choosing $\gamma$.

When $\alpha$ and $\gamma$ are set equal to zero, the TWR is equal tothe standard headcount employment rate, that is $T W R(0,0)=G E R(0)$. The headcount of people involved in either or both types of work, normalised by the total population, can be obtained by taking $\gamma>0$ and $\alpha=0$. When $\alpha=1, T W R$ averages across working-age people the (normalised) hours of employment for $\gamma=0$, so that $T W R(1,0)=G E R(1)$, and the (normalised) total hours of work for $\gamma=1$. These are the four main cases on which we focus in this paper, although the general formulation (2) allows the parameters $\alpha$ and $\gamma$ to take other intermediate values, so to assess differently the hours spent in employment and in OUP work and theirrelative weight. Our choice to focus mainly on the two extreme values for $\gamma, 0$ and 1 , follows naturally from the standard way of constructing labour statistics: either we do not value household production and set $\gamma$ equal to 0 , or we value it and simply add up hours spent in the two types of work, taking $\gamma$ equal to 1 . However, in Section 5.3 we show how empirical results would change by setting intermediate values of $\gamma$.

\section{The data: the multinational time use study}

In this paper, we use the harmonized time use microdata made available by the University of Oxford in the con- 
text of the Multinational Time Use Study (MTUS). ${ }^{5}$ We focus on France, Germany, Italy, the Netherlands, the United Kingdom (UK) and the United States (US). We select these countries because they are at a comparable, advanced, stage of economic and social development, but at the same time are sufficiently heterogeneous in their economic structure, institutional settings and cultural tradition to show different patterns in the allocation of labour among household members and during the week (e.g. the importance of female housework in Italy, or the widespread use of part-time work in the Netherlands). Last but not least, for all these countries the sample size is large enough to produce reliable estimates. We select the surveys conducted from 1995 to 2005 and exclude those for subsequent years (available only for some countries, such as the US) to avoid that country estimates are unequally affected by changes in time allocation induced by the global financial crisis. Table 1 reports the sample size for each country and year used in this paper.

Typically, time use surveys are based on daily diaries of individuals. Time use diaries refer to a 24-hour period of a specific day in the week. Respondents are asked to record all their activities (usually in 10 minutes time intervals), possibly distinguishing between primary and secondary activities when they are carried out contemporaneously. If an activity is not reported because the respondent did not carry it out, that activity is assigned a 0 minute time interval. Some activities are imputed by national statistical offices but there is no harmonised imputation procedure. As in labour force surveys, people are required to report their activities independently of whether they are carried out in the regular or hidden economy. The under-reporting of irregular activities is common to all surveys which ask people to report what they do. However, in time use surveys the under-reporting might be possibly lower than in labour force surveys, because of the detailed recording of the time spent in various activities (Hirway and Jose 2011) or because respondents may be less afraid that their answers could be used for administrative controls by tax or social security authorities.

As the detailed list of possible activities can vary by country, the MTUS provides a large set of 69 activities as well as their aggregation in 29 relatively broad and homogenous categories (see Table 5 in the Appendix). This reclassification of activities in 29 categories was carried out by the MTUS team and is contained in the "MTUS simple file", which is the outcome of a considerable effort at data cleaning and harmonisation. Since in our analysis we do not consider the time spent in each activity, but we look at aggregates of market and non-market activities we use the aggregate MTUS simple file. In the MTUS simple file, the

\footnotetext{
5 The data are available at http://www.timeuse.org/mtus/ after registra-
} tion.
Table 1 MTUS Sample size by country and year

\begin{tabular}{lllllll}
\hline Year & France & Germany & Italy & \multicolumn{2}{l}{ Netherlands UK } & US \\
\hline 1995 & - & - & - & 19,824 & 1,502 & - \\
1998 & 10,971 & - & - & - & - & - \\
1999 & 1,424 & - & - & - & - & - \\
2000 & - & - & - & 10,472 & 6,433 & - \\
2001 & - & 20,343 & - & - & 8,674 & - \\
2002 & - & 7,697 & 27,019 & - & - & - \\
2003 & - & - & 8,723 & - & - & 17,242 \\
2004 & - & - & - & - & - & 11,515 \\
2005 & - & - & - & 12,446 & 3,686 & 10,893 \\
\hline
\end{tabular}

Source: authors' elaboration on data from MTUS

single observation unit is the time spent by individuals, but only in the primary activity (in minutes). Standard socio-demographic characteristics (gender, age, main activity status, marital status, etc.) and household characteristics (number of children, number of household members) are available for each person in the sample. MTUS reports only good quality diaries, that is diaries for which it is possible to recover all the activities carried out by individuals during the sampled day: the dataset, however, provides also weights to adjust for the exclusion of incomplete diaries. We calculate all statistics using these weights.

For simplicity, and consistently with the practice in labour market statistics, our estimates consider only primary activities. In time use data, the identification of primary and secondary activities is left to respondents. This may introduce some heterogeneity in the data, as the relevance of secondary activities can vary according to household specific arrangements, individual preferences, individual effort, and also by country, as a result of different institutions or cultural values. As we focus on total OUP work, the misclassification of activities between primary and secondary affects our estimates only when one activity is performed for the market and the other one for own use. We do not control for these cases. Accounting for secondary activities is left for future research.

We stick to the practice adopted in standard employment statistics to focus on the working-age population, which is commonly identified as composed of people aged between 15 and 64 years. According to the ILO official criteria, a person is employed if he or she has worked at least one hour during the week preceding the interview. In this paper, since we have only daily reference periods, we define the condition of being employed as a dummy equal to 1 if the person has worked at least one hour in the sampled day and zero otherwise. This criterion is more restrictive than the standard definition: it excludes people who have a job but were not at work in the day of the interview, due to sickness, vacation, or simply a working time spread on different days of the week. However, as long as the sample 
is representative of the total working-age population in each day of the week, aggregation at the country level should allow us to limit the impact of measurement errors.

The information available from the MTUS maps rather closely the description of own-use production work given in the 2013 Resolution of the International Conference of Labour Statisticians (see Fig. 2). We hence identify OUP work with the following eight activities among the 29 included in the MTUS simple file (see Table 5): (1) food preparation; (2) cleaning home and similar activities; (3) child care (including child/adult care travel); (4) care of other household members and elderly care; (5) maintenance of home and vehicles (including collecting fuel); (6) purchase of goods; (7) gardening; (8) pet care (including walk dogs). ${ }^{6}$ Table 6 in the Appendix reports, by country, the time spent in each activity, expressed as fraction of the day.

We define the daily intensity in employment, in OUP work, and in total work as the ratio of the time spent in each activity to the total of 24 hours. Participation in employment and OUP work requires that someone spends at least 1 hour per day in either type of activities.

\section{Results}

\subsection{Headcount participation rates}

As individuals can engage in both employment and OUP work, the headcount indicators must consider the combination of both types of productive processes. The columns of Table 2 report, for the total and by sex, the share of people: (1) in both employment and OUP work; (2) in employment only; (3) in OUP work only; and (4) not in work. Our estimates are based on pooled data across the available waves. $^{7}$

On average, around 40 per cent of the total working-age population has a paid job and engages in household production. This share is higher in the Netherlands than in the other countries, possibly because of the very high incidence of part-time work. An extreme pattern of work division within the household emerges for Italy, which stands out for the highest shares of men engaged only in employment, on one side, and women working only at home, on the other. The proportion of people without any work activity is around 10 per cent on average, but it reaches 12.6 per

\footnotetext{
${ }^{6}$ In the 2013 Resolution time spent travelling to and from work is excluded from both employment and OUP activities.

7 As a robustness exercise, using the Dutch and British data, we replicate the Fig. 3, 4 and 5 discussed below separately for 1995 and 2005 (see Fig. 8, 9 and 10 in the Appendix). Understandably, there are differences: for instance, the intensity of total work has gone down in both countries between the two years. However, the overall picture is qualitatively consistent with the results based on pooled data.
}

cent in Italy and France, where the high male share drives it. Those without any work activity are mainly people aged 15-16 years, students, male, and living in urban areas.

Table 3 reports the rates of employment, OUP work, and total work, based on MTUS data, together with the standard employment rates drawn from Labour Force Survey data (LFS) for the corresponding years. ${ }^{8}$ The MTUS employment rates in the second column (the sum of columns 1 and 2 in Table 2) are sufficiently close to the LFS rates in the first column, given the many differences in surveys and definitions. Overall, the cross-country picture is unaffected, also by sex: the employment rate is higher in the Netherlands, the UK and the US than in the other countries, and it is lowest in Italy; the participation of Italian women, whose rate is at least 20 percentage points lower than in the first three countries, explains the gap. However, there are perceptible differences between the two sources. The MTUS rates are consistently higher than the LFS rates in the US, whereas the opposite happens in the UK and Italy. The largest discrepancy is found for the employment rate of Dutch women, who appear to have a much higher probability of having a paid job in the MTUS than in the LFS (7.5 percentage points). Understanding the discrepancies between the LFS and MTUS figures is beyond the scope of this paper. However, this evidence suggests that some work of reconciliation may be necessary before data from time use surveys are routinely used to construct labour statistics.

Cross-country differences are remarkably smaller for the OUP work rates in the third column of Table 3 (the sum of columns 1 and 3 in Table 2) than for the employment rates. These headcount ratios vary between 60.8 per cent in Italy and 66.4 per cent in Germany, a range of 6 points that compares with the over 20 points of the employment rates. On the other hand, sex differences are larger for OUP work than for employment, and reach a maximum in Italy.

The total work rate in the fourth column (the sum of columns 1 to 3 in Table 2) is the share of working-age people who are engaged in production for the market, for own-use, or both. This rate falls within a range of about 5 percentage points around 90 per cent. The inclusion of OUP work reduces then differences in work participation across countries. The strong improvement in the figure for Italy is not due to men, who are characterised by the lowest rates in both types of work, but entirely to women, who compensate the low participation in the market with a strong presence in the household production.

\footnotetext{
${ }^{8}$ As the MTUS data do not include information on stratification variables, we are unable to compute exact standard errors. However, in consideration of the large number of observations and given that we mainly focus on sample averages, we are confident that the estimates are sufficiently precise.
} 
Table 2 Share of population in employment and OUP work, people aged 15-64 (per cent of working-age persons)

Table 3 Headcount rates of employment, OUP work and total work (per cent of workingage persons)

\begin{tabular}{llllll}
\hline Country and sex & $\begin{array}{l}\text { Employment } \\
\text { and OUP } \\
\text { work }\end{array}$ & $\begin{array}{l}\text { Employment } \\
\text { only }\end{array}$ & $\begin{array}{l}\text { OUP work } \\
\text { only }\end{array}$ & No work & Total \\
\hline Men and Women & & & & & \\
France & 35.1 & 24.7 & 27.5 & 12.6 & 100.0 \\
Germany & 40.1 & 23.5 & 26.2 & 10.1 & 100.0 \\
Italy & 26.7 & 26.6 & 34.1 & 12.6 & 100.0 \\
Netherlands & 45.3 & 27.9 & 19.0 & 7.8 & 100.0 \\
UK & 39.5 & 29.3 & 23.2 & 8.0 & 100.0 \\
US & 44.4 & 30.6 & 17.6 & 7.4 & 100.0 \\
Men & & & & & \\
France & 27.7 & 40.0 & 16.8 & 15.5 & 100.0 \\
Germany & 37.4 & 36.4 & 14.3 & 11.9 & 100.0 \\
Italy & 21.3 & 45.0 & 16.9 & 16.9 & 100.0 \\
Netherlands & 36.4 & 42.8 & 11.8 & 9.1 & 100.0 \\
UK & 33.2 & 41.7 & 14.7 & 10.4 & 100.0 \\
US & 40.7 & 40.9 & 9.9 & 8.5 & 100.0 \\
Women & & & & & \\
France & 42.5 & 9.7 & 38.0 & 9.8 & 100.0 \\
Germany & 42.4 & 12.4 & 36.5 & 8.7 & 100.0 \\
Italy & 31.9 & 8.8 & 50.9 & 8.4 & 100.0 \\
Netherlands & 52.2 & 16.5 & 24.5 & 6.8 & 100.0 \\
UK & 45.7 & 17.2 & 31.6 & 5.6 & 100.0 \\
US & 47.9 & 20.7 & 25.0 & 6.4 & \\
\hline
\end{tabular}

Source: authors' elaboration on data from MTUS

\begin{tabular}{|c|c|c|c|c|}
\hline \multirow[t]{2}{*}{ Country and sex } & Employment & $\begin{array}{l}\text { Employment } \\
T W R(0,0)\end{array}$ & OUP work & $\begin{array}{l}\text { Total work } \\
T W R(0,1)\end{array}$ \\
\hline & LFS & MTUS & MTUS & MTUS \\
\hline \multicolumn{5}{|l|}{ Men and women } \\
\hline France & 60.7 & 59.9 & 62.6 & 87.4 \\
\hline Germany & 65.7 & 63.6 & 66.4 & 89.9 \\
\hline Italy & 55.1 & 53.3 & 60.8 & 87.4 \\
\hline Netherlands & 70.3 & 73.3 & 64.3 & 92.2 \\
\hline UK & 70.7 & 68.8 & 62.8 & 92.0 \\
\hline US & 71.3 & 75.0 & 62.0 & 92.6 \\
\hline \multicolumn{5}{|l|}{ Men } \\
\hline France & 67.7 & 67.7 & 44.5 & 84.5 \\
\hline Germany & 72.8 & 73.8 & 51.8 & 88.1 \\
\hline Italy & 68.8 & 66.2 & 38.2 & 83.1 \\
\hline Netherlands & 79.1 & 79.1 & 48.1 & 90.9 \\
\hline UK & 77.1 & 74.9 & 47.8 & 89.6 \\
\hline US & 77.2 & 81.6 & 50.7 & 91.5 \\
\hline \multicolumn{5}{|l|}{ Women } \\
\hline France & 53.5 & 52.2 & 80.3 & 90.2 \\
\hline Germany & 58.3 & 54.8 & 79.0 & 91.3 \\
\hline Italy & 41.5 & 40.7 & 82.9 & 91.6 \\
\hline Netherlands & 61.2 & 68.7 & 76.7 & 93.2 \\
\hline UK & 64.3 & 62.9 & 77.3 & 94.4 \\
\hline US & 65.5 & 68.6 & 73.0 & 93.6 \\
\hline
\end{tabular}

Source: authors' elaboration on data from MTUS and LFS. The LFS values are simple averages for the same years as the corresponding MTUS's 

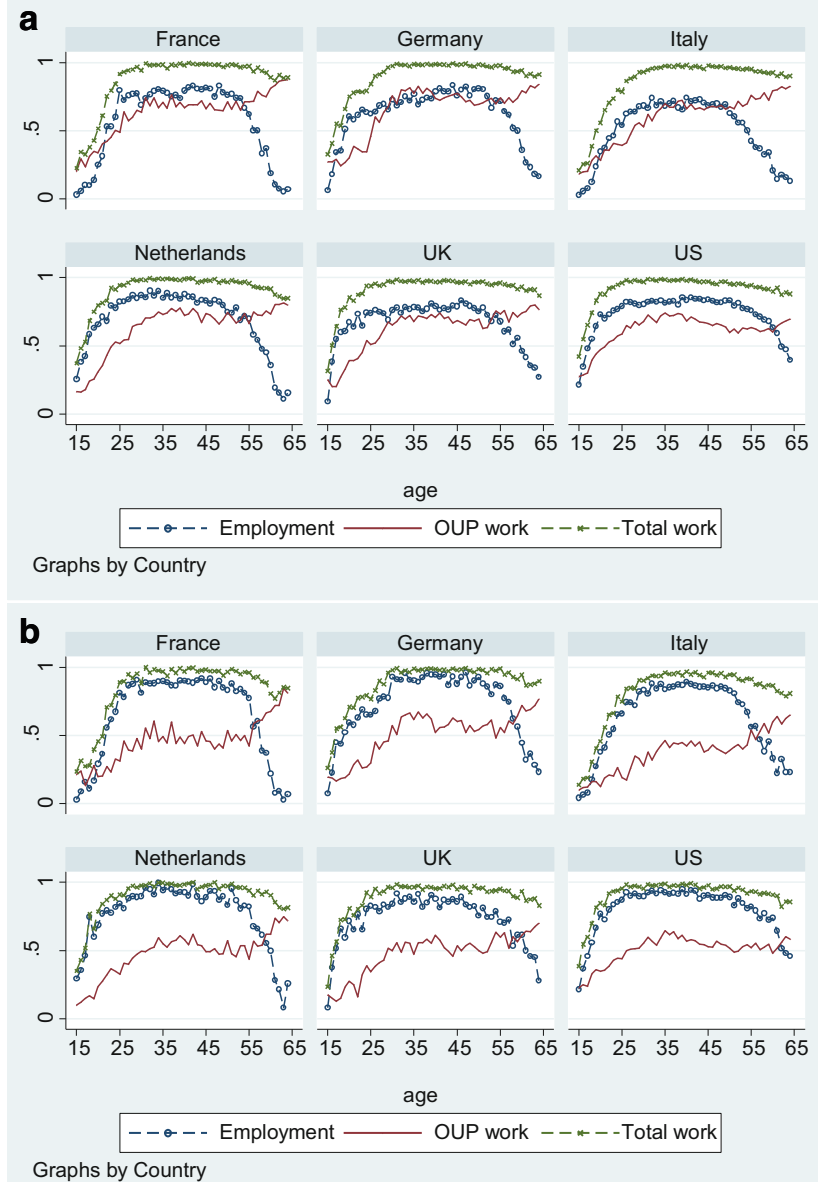

c
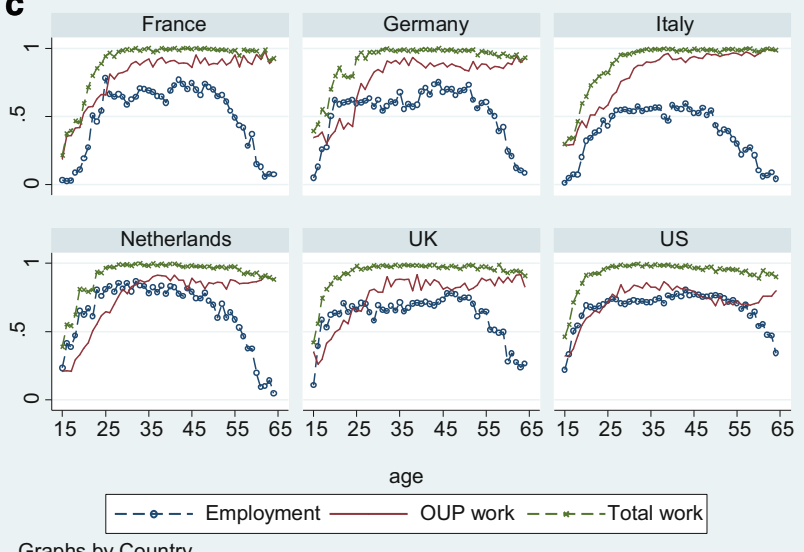

Graphs by Country

Fig. 3 Age profiles of headcount rates of employment, OUP work and total work, by country; a men and women; b men; c women (Source: authors' elaboration on data from MTUS)

The comparison between the index $T W R(0,0)=$ $G E R(0)$ in the second column and the index $T W R(0,1)$ in the fourth column highlights how including household production raises the proportion of people engaged in any work activity very close to 1 . Yet, the headcount rates for total work are not totally uninformative: not only cross- country differences do not vanish, but also the disaggregation by age and sex reveals diverse patterns. Fig. 3 shows theage profile of the total work rate, together with the employment and OUP work rates. In all countries, the headcount rate for OUP workis remarkably smaller for young individualsthan for older people. It reaches 50 per cent between 25 and 30 years of age, which isthe age at which people typically end studying and start living alone, except for Italy, where this happens afterage 30 . Aside from the US, the OUP work rate does not decreaseafter age 55 likethe employment rate, but rather it steadily goes up. In all countries, theheadcountrate for total work approaches 1after age 30 and then declines slightly after age 50. This decline characterises only men, who partially substitute employment in the market with OUP work as they aged. As OUP work is so more widespread among them, for women there is virtually no drop in the total work rate.

In brief, the analysis of these indicators of the extensive participation margin suggests that the diversity in total work across countries is not negligible, but is small in comparison to that in employment. These differences are likely to reflect dissimilarities in the weight of the young in the total population and the variety in the timing of family formation and fertility.

\subsection{Intensity-weighted participation rates}

Time spent working per day isour measure of the intensive margin of work. Unlike the headcount ratio, it allows usto consider not only how many people are at work, but also how much they work. In Table 4 we report the fractions of the day spent in work for market and own-use production. As for the standard dichotomous index, the intensityweighted employment rate in the first column, which is $T W R(1,0)=G E R(1)$, is higher in the UK and the US than in the other countries. Differently from the headcount indices in Table 3, however, accounting for hours of work pushes Italy ahead of France, Germany and the Netherlands. Thus, the higher number of hours worked by Italians in the market compensates for the lower proportion of people in employment. The comparison of the intensity-weighted and standard headcount indices reveals that this result is mainly due to the male component of the workforce. This country re-ranking of the employment rates survives to the inclusion of OUP work, as shown by the intensity-weighted rate of total work $T W R(1,1)$ in the last column of Table 4 . The intensity of OUP work is rather similar across countries if we look at the means, not if we look at the breakdown by sex. Women spend in household work about twice the hours spent by men, except for Italy where this ratio rises above 3 . 
Table 4 Intensity-weighted rates of employment, OUP work and total work (per cent of 24 hours)

\begin{tabular}{llll}
\hline Country and sex & $\begin{array}{l}\text { Employment } \\
T W R(0,1)\end{array}$ & OUP work & $\begin{array}{l}\text { Total work } \\
T W R(1,1)\end{array}$ \\
\hline Men and Women & & & \\
France & 13.3 & 13.1 & 26.4 \\
Germany & 12.3 & 13.7 & 26.0 \\
Italy & 13.8 & 14.3 & 28.1 \\
Netherlands & 12.7 & 13.7 & 26.4 \\
UK & 14.7 & 13.5 & 28.2 \\
US & 16.7 & 13.8 & 30.4 \\
Men & & & \\
France & 16.4 & 7.9 & 24.4 \\
Germany & 16.1 & 9.4 & 25.4 \\
Italy & 18.9 & 6.7 & 25.6 \\
Netherlands & 17.9 & 9.0 & 26.9 \\
UK & 18.3 & 9.3 & 27.6 \\
US & 19.8 & 10.2 & 30.0 \\
Women & & & \\
France & 10.1 & 18.2 & 28.3 \\
Germany & 9.0 & 17.5 & 26.5 \\
Italy & 8.9 & 21.6 & 30.6 \\
Netherlands & 8.7 & 17.3 & 26.0 \\
UK & 11.2 & 17.6 & 28.7 \\
US & 13.6 & 17.2 & 30.8 \\
\hline Sorce: & &
\end{tabular}

Source: authors' elaboration on data from MTUS

The age profiles of the intensity-weighted rates of total work show that in the US and in Italy people aged between 30 and 55 work more than in other countries (Fig. 4). The difference persists also after age 55. However, it depends on high employment intensity of both men and women in the US, but on very high OUP intensity of women of aged 55 years or more in Italy (similar evidence in also found by Fang et al. 2014).

The distribution of intensity dramatically changes when we compare employment to total work. Fig. 5 reports the kernel density estimates of the two distributions for all countries. ${ }^{9}$ To ease comparisons, we do not show the hikes corresponding to those who have no employment. Unsurprisingly, the inclusion of OUP work shifts the mass away from zero intensity towards the right in all countries: the mode of the total work distribution is around 40 per cent of the day, which is more than nine and a half hours.

Fig. 6 compares the same kernel density distributions across countries, separately for employment intensity (top panel) and total work intensity (bottom panel). The dissimilarity is noticeable for employment intensities around zero and approximately 8 hours ( 0.33 on the horizontal axis), but

${ }^{9}$ Kernel density estimation is a non-parametric way to estimate onedimensional smooth density functions (e.g Sheather and Jones 1991).
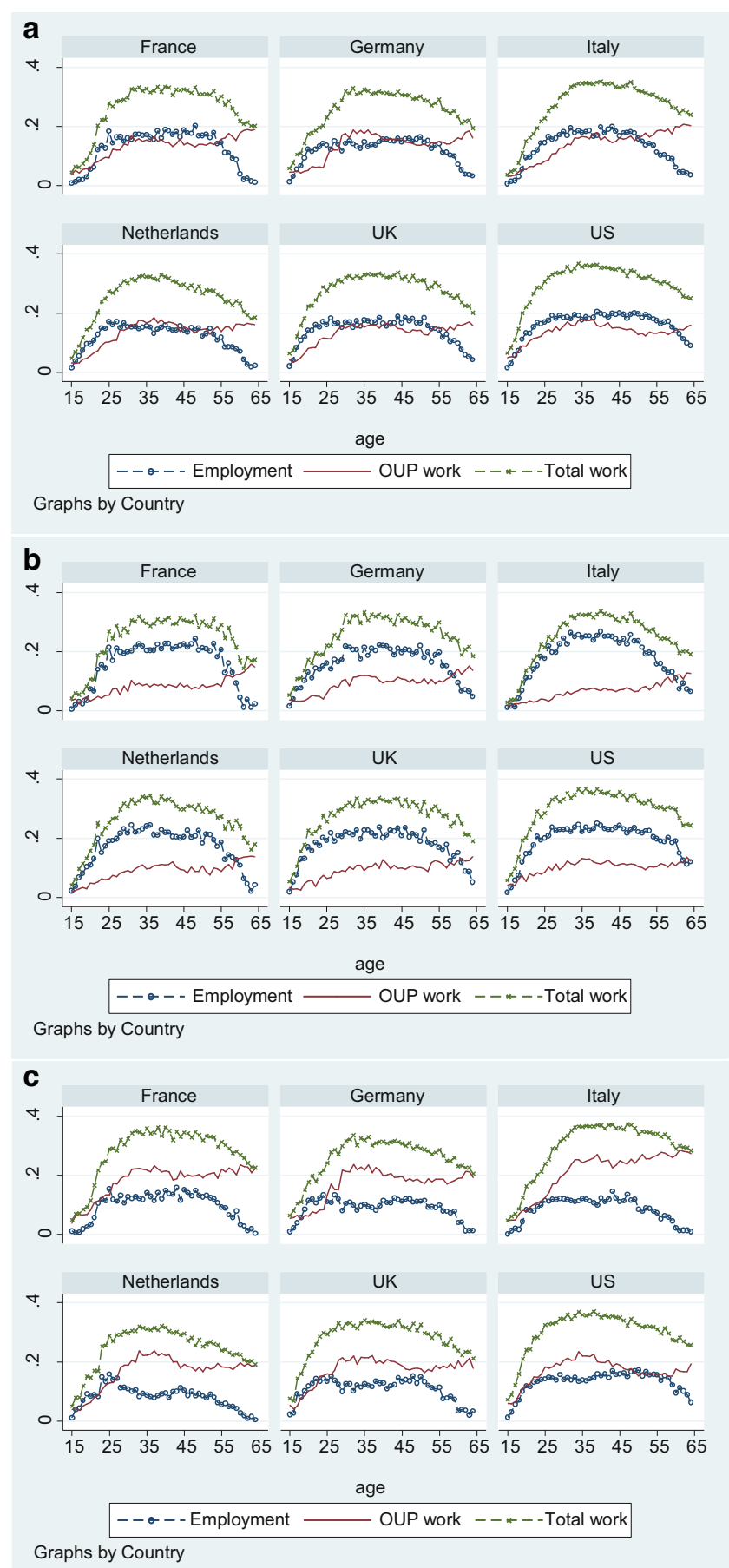

Fig. 4 Age profiles of intensity-weighted rates of employment, OUP work and total work, by country; a men and women; $\mathbf{b}$ men; $\mathbf{c}$ women (Source: authors' elaboration on data from MTUS)

is less pronounced for total work intensity. Cross-country differences in work participation narrow significantly when we take a broader concept of work that includes household production. 


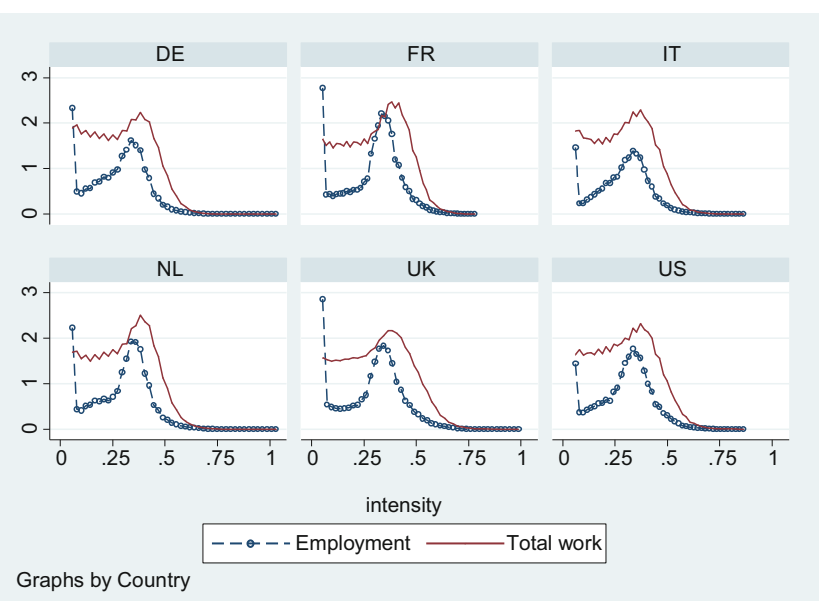

Fig. 5 Distribution of intensity of employment and total work, by country (Source: authors' elaboration on data from MTUS)
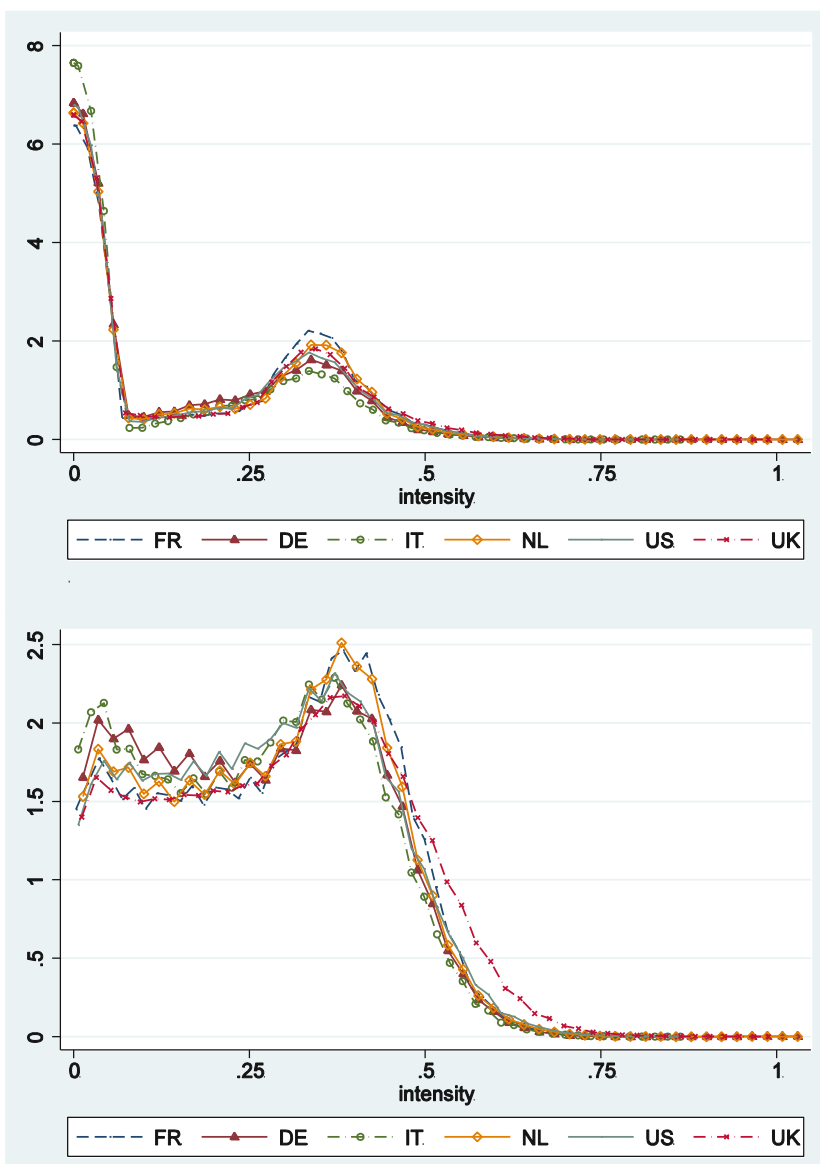

Fig. 6 Distribution of intensity of employment and total work; a employment intensity b total work intensity (Source: authors' elaboration on data from MTUS)

\subsection{The value of $\gamma$}

So far, we have considered solely the two extreme values for $\gamma, 0$ and 1. As mentioned above, the value of $\gamma$ rep-

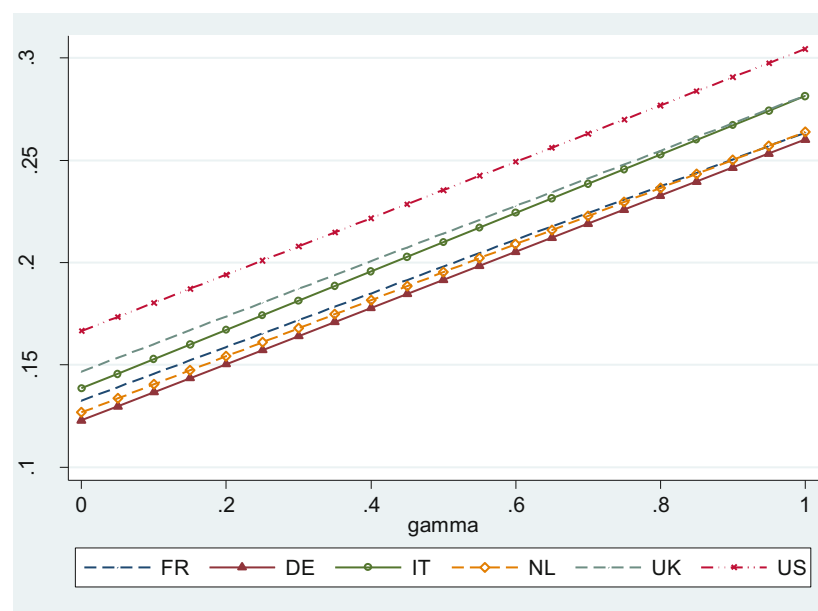

Fig. 7 Total work for different values of the parameter $\gamma$ (Source: authors' elaboration on data from MTUS)

resents the conversion rate of one hour of OUP work into market work anddetermines the social evaluation of time spent in household production. Without making any specific assumption on the most appropriate way to set $\gamma$, in Fig. 7 we show how varying $\gamma$ between 0 and 1 affects the intensity-weighted rate of total work $(\alpha=1)$. Somewhat surprisingly, different values of $\gamma$ do not changethe rank of countries. Yet, in some cases, there is some narrowing of the gap observed when only employment matters. As $\gamma$ moves towards 1 , the Dutch total work intensity approaches the French figure, and the Italian rate reaches the UK rate. The US clearly leads the ranking for any value of $\gamma$, confirming the different preferences as regards the allocation of time between the two sides of the Atlantic.

\section{Conclusions}

There is no doubt that household production, as opposed to market production, is a crucial component in the evaluation of a country's output and well-being. While methods for adjusting the estimates of national and individual incomes have received much attention, leading to the construction of satellite accounts to complement the SNA, less is known as regards the implications for assessing work participation levels. In this paper, we have proposed a general framework, which allows us to account for household work by focusing on work intensity, as measured by actual hours of work, rather than on the dichotomous distinction between employed and non-employed. We have described a class of indices that encompasses headcount and intensity-weighted rates of work participation and allows for the possibility to sum OUP work and employment. The empirical analysis using time use data shows that the ranking of countries is sensitive to the shift from headcounts to intensity-weighted 
indices, and that the inclusion of OUP work changes considerably the picture on the work burden of men and women. The comparison between the MTUS and LFS data show that there are discrepancies: this points to the need to work on the harmonisation and integration of the two sources.

Coyle (2014: 140) argues that we should rethink the meaning of "the economy". She suggests that this is also related to the fact that "... the boundary between paid work in the market and unpaid work has become fuzzier the more people contribute to voluntary value-creation (Wikipedia and Linux being the canonical example), or draw on their 'leisure' activities for their paid work (having a brilliant idea while out with friends), or mingle the two (a landscape gardener practising new designs on family members before selling them to clients)". There are older reasons to reconsider such a boundary, since certain household activities have traditionally contributed to well-being and to create economic value as much as market jobs, e.g. in the care of children and the elderly. This paper has attempted to cast this concern into a standard framework for the statistical analysis of the labour market. It has admittedly refrained from accounting for the household dimension of the problem as well as for a second important component of unpaid work, voluntary work. Further research is needed on both aspects.

Acknowledgements We thank two anonymous reviewers and Conchita D'Ambrosio, Ignazio Visco and participants in the IARIW 33rd General Conference, Rotterdam 2014, for helpful comments on an earlier draft of the paper. In this article we use the Multinational Time Use Study, Versions World 5.5.3, 5.80 and 6.0 (released October 2012), created by Jonathan Gershuny and Kimberly Fisher. The views expressed here are solely ours; in particular, they do not necessarily reflect those of the Bank of Italy.

Open Access This article is distributed under the terms of the Creative Commons Attribution 4.0 International License (http:// creativecommons.org/licenses/by/4.0/), which permits unrestricted use, distribution, and reproduction in any medium, provided you give appropriate credit to the original author(s) and the source, provide a link to the Creative Commons license, and indicate if changes were made.

\section{Appendix}

Table 5 List of variables in the MTUS dataset

\begin{tabular}{|c|c|c|}
\hline $\begin{array}{l}\text { Variable } \\
\text { name }\end{array}$ & Activity & $\begin{array}{l}\text { OUP } \\
\text { work }\end{array}$ \\
\hline Sleep & Sleep and naps & No \\
\hline Eatdrink & Meals or snacks & No \\
\hline Selfcare & Wash, dress, care for self & No \\
\hline Paidwork & Paid work and related activities & No \\
\hline Educatn & Schooling, education, homework & No \\
\hline Foodprep & $\begin{array}{l}\text { Food preparation, cook, wash/put away } \\
\text { dishes }\end{array}$ & Yes \\
\hline Cleanetc & Cleaning, laundry, regular housework & Yes \\
\hline Maintain & $\begin{array}{l}\text { Maintain home/vehicle, including collect } \\
\text { fuel }\end{array}$ & Yes \\
\hline Shopserv & Purchase goods, consume services & Yes \\
\hline Garden & Gardening/pick mushrooms & Yes \\
\hline Petcare & Pet care (including walk dogs) & Yes \\
\hline Eldcare & Look after adults needing help or care & Yes \\
\hline Pkidcare & $\begin{array}{l}\text { Physical, medical, supervisory, routine } \\
\text { child care }\end{array}$ & Yes \\
\hline Ikidcare & $\begin{array}{l}\text { Play/sports with, read/talk to child, help } \\
\text { with homework }\end{array}$ & No \\
\hline Religion & Worship, religion, and prayer & No \\
\hline Volorgwk & Voluntary, civic, organisational activities & No \\
\hline Commute & Travel to/from work or education & No \\
\hline Travel & Travel & No \\
\hline Sportex & Sport or exercise & No \\
\hline Tvradio & Watch television, listen to radio & No \\
\hline Read & Read & No \\
\hline Compint & E-mail, web, program, computer games & No \\
\hline Goout & $\begin{array}{l}\text { Cinema/theatre, sport match, away from } \\
\text { home leisure }\end{array}$ & No \\
\hline Leisure & Other free time leisure & No \\
\hline Missing & No activity reported & No \\
\hline Restrnt & Restaurant, café, bar, pub & No \\
\hline Eatatwrk & Meals at work or school & No \\
\hline Compgame & Play computer games & No \\
\hline Caretrav & Child/adult care travel & No \\
\hline
\end{tabular}

Source: MTUS

Table 6 Share of time spent in OUP elementary activities (\%)

\begin{tabular}{|c|c|c|c|c|c|c|}
\hline Elementary activities & France & Germany & Italy & Netherlands & UK & US \\
\hline Food preparation & 3.4 & 3.0 & 4.1 & 3.4 & 3.2 & 2.1 \\
\hline Cleaning home and similar activities & 3.7 & 3.4 & 4.3 & 2.7 & 3.1 & 3.4 \\
\hline Care of other household members, elderly care & 0.0 & n.a. (1) & n.a. (1) & 0.4 & 0.1 & 0.9 \\
\hline Child care & 1.8 & 1.8 & 1.5 & 2.4 & 2.6 & 3.4 \\
\hline Maintain home and vehicles & 0.3 & 2.3 & 1.2 & 1.0 & 0.9 & 0.5 \\
\hline Purchase goods, consume services & 2.3 & 2.2 & 2.4 & 2.1 & 2.1 & 2.2 \\
\hline Gardening & 0.9 & 0.8 & 0.6 & 0.5 & 0.6 & 0.9 \\
\hline Pet care & 0.3 & n.a. (1) & n.a. (1) & 0.6 & 0.6 & 0.3 \\
\hline
\end{tabular}

Source: MTUS. (1) Included in other house activities. 


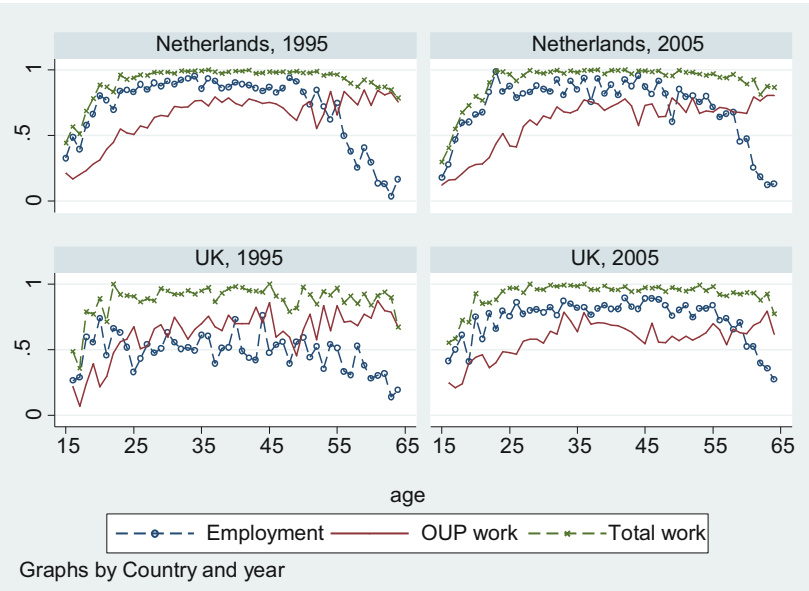

Fig. 8 Age profiles of headcount rates of employment, OUP work and total work in the Netherlands and the UK in 1995 and 2005 (men and women)

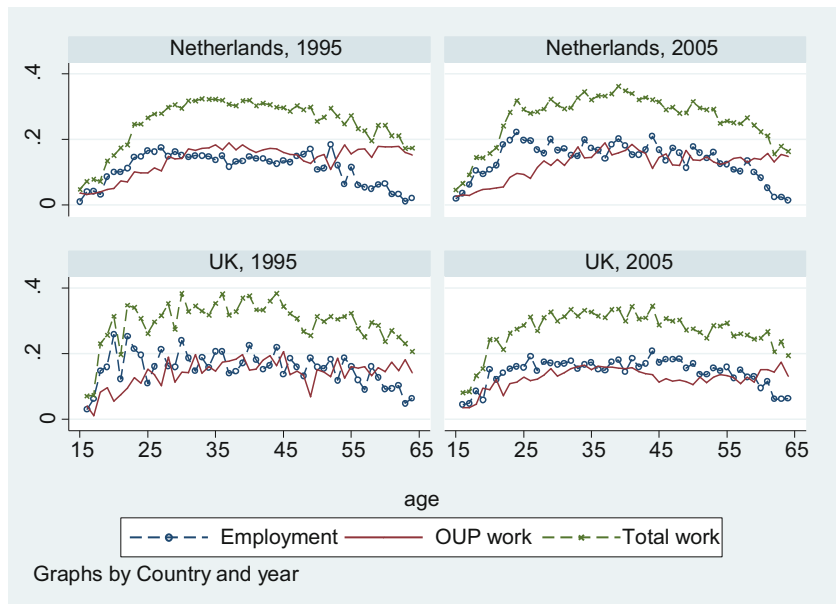

Fig. 9 Age profiles of intensity-weighted rates of employment, OUP work and total work in the Netherlands and the UK in 1995 and 2005 (men and women)

\section{References}

Baxter, M., Jermann, U.J.: Household production and the excess sensitivity of consumption to current income. Am Econ Rev 89(4), 902-920 (1999)

Becker, G.S.: A theory of the allocation of time. Econ J 75(299), 493-517 (1965)

Benhabib, J., Rogerson, R., Wright, R.: Homework in macroeconomics: household production and aggregate fluctuations. J Polit Econ 99(6), 1166-1187 (1991)

Brandolini, A., Viviano, E.: Behind and beyond the (head count) employment rate. J Royal Stat Soc Ser A 179(3), 657-681 (2016a)

Brandolini, A., Viviano, E.: Extensive versus intensive margin: changing perspective on the employment rate. In: Atkinson, A.B., Guio, A.C., Marlier, E. (eds.) Monitoring social Europe. Publications Office of the European Union, Luxembourg (2016b)

Bridgman, B., Dugan, A., Lal, M., Osborne, M., Villones, S.: Accounting for household production in the national accounts, 1965-2010. Surv Curr Bus 92(5), 23-36 (2012)
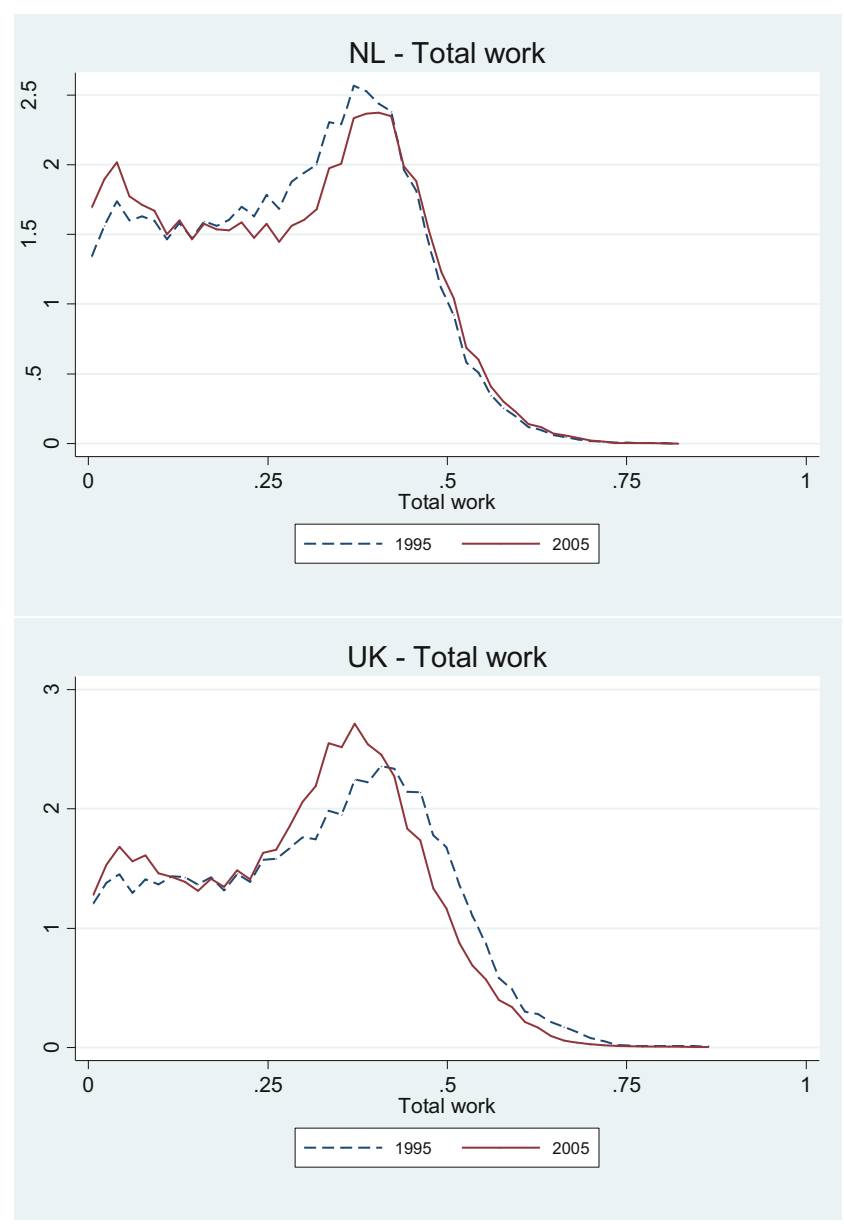

Fig. 10 Distribution of intensity of total work in the Netherlands and the UK in 1995 and 2005 (men and women)

Burda, M., Hamermesh, D.S., Weil, P.: Total work, gender, and social norms. J Popul Econ 26(1), 239-261 (2013)

Chadeau, A.: Measuring household activities: some international comparisons. Rev Income Wealth 31(3), 237-253 (1985)

Connelly, R., Kimmel, J.: Mothers' time choices caregiving, leisure, home production, and paid work. J Hum Resour 42(3), 643-681 (2007)

Coyle, D.: GDP a brief but affectionate history. Princeton University Press, Princeton (2014)

European Communities, International Monetary Fund, Organisation for Economic Co-operation and Development, United Nations, World Bank: System of National Accounts 2008. New York (2009)

Fang, Lei, McDaniel, C.: Home hours in the United States and Europe, federal reserve Bank of Atlanta. Working paper, vol. 2014-5. (2014)

Fitzgerald, J.M., Swenson, M.S., Wicks, J.H.: Valuation of household production at market prices and estimation of production functions. Rev Income Wealth 42(2), 165-180 (1996)

Frick, J.R., Grabka, M.M., Groh-Samberg, O.: The impact of home production on economic inequality in Germany. Empir Econ 43(3), 1143-1169 (2012)

Gershuny, J., Fisher, K.: Multinational time use study. Centre for Time Use Research, University of Oxford, Oxford (2013) 
Goldschmidt Clermont, L.: Monetary valuation of non-market productive time: methodological considerations. Rev Income Wealth 39(4), 419-433 (1993)

Goldschmidt-Clermont, L.: Unpaid work in the household. International Labour Office, Geneva (1982)

Graham, J.W., Green, C.A.: Estimating the parameters of a household production function with joint products. Rev Econ Stat 66(2), 227-282 (1984)

Gronau, R.: Home production: a forgotten industry. Rev Econ Stat 62(3), 408-416 (1980)

Hamermesh, D.S.: Time to eat: household production under increasing income inequality. Am J Agric Econ 89(4), 852-863 (2007)

Hirway, I., Sunny, J.: Understanding women's work using time use statistics: the case of India. Fem Econ 17(4), 67-92 (2011)

International Conference of Labour Statisticians (ICLS): "Resolution concerning statistics of the economically active population, employment, unemployment and underemployment, adopted by the Thirteenth International Conference of Labour Statisticians (ILO Resolution, 1 October 1982). http://www.ilo.org/global/ statistics-and-databases/standards-and-guidelines/resolutionsadopted-by-international-conferences-of-labour-statisticians/ WCMS_087481/lang-en/index.htm

International Conference of Labour Statisticians (ICLS): "Resolution concerning statistics of work, employment and labour underutilization. Adopted by the Nineteenth International Conference of Labour Statisticians (ILO Resolution, 21 November 2013). http://www.ilo.org/global/statistics-and-databases/ standards-and-guidelines/resolutions-adopted-by-internationalconferences-of-labour-statisticians/WCMS_230304/lang-en/ index.htm

Jenkins, S.P., O'Leary, N.C.: Household income plus household production: the distribution of extended income in the U.K. Rev Income Wealth 42(4), 401-419 (1996)
Landefeld, S.J., Fraumeni, B.M., Vojtech, C.M.: Accounting for household production: a prototype satellite account using the American time use survey. Rev Income Wealth 55(2), 205-225 (2009)

National Research Council: Beyond the market: designing nonmarket accounts for the United States. The National Academies Press, Washington, DC. (2005)

Nordhaus, W., Tobin, J.: Is growth obsolete? In: Moss, M. (ed.) The measurement of economic and social performance, studies in income and wealth, vol. 38, pp. 509-564. National Bureau of Economic Research, New York (1973)

Sheather, S.J., Jones, M.C.: A reliable data-based bandwidth selection method for kernel density estimation. J Royal Stat Soc Ser B 53(3), 683-690 (1991)

Suh, J., Folbre, N.: Valuing unpaid child care in the US: a prototype satellite account using the American time use survey. Rev Income Wealth (2015). doi:10.1111/roiw.12193

Weinrobe, M.: Household Production and National Production: An Improvement of the Record. Rev Income Wealth 20(1), 89-102 (1974)

Mr. Andrea Brandolini is head of the Statistical Analysis Directorate of the Bank of Italy. He has published papers on the analysis of poverty and income and wealth distribution, the measurement of well-being, issues in labour economics, and the history of economic thought (for a partial list, see https://ideas.repec.org/e/pbr18.html).

Ms. Eliana Viviano is a senior economist in the Economic Structure and Labour Market Division (Structural Economic Analysis Directorate, Bank of Italy). She has published papers on issues in labour economics, labour and product market reforms, household finance (for a partial list, see https://ideas.repec.org/e/pvi190.html). 